Article

\title{
Aspects to Be Considered when Implementing Technology-Enhanced Learning Approaches: A Literature Review
}

\section{Patrick Schweighofer ${ }^{1, *}$ and Martin Ebner ${ }^{2}$}

1 Information Technologies \& Business Informatics, CAMPUS 02 University of Applied Science, Körblergasse 126, 8010 Graz, Austria

2 Social Learning, Graz University of Technology, Münzgrabenstraße 35A/I, 8010 Graz, Austria; E-Mail: martin.ebner@tugraz.at

* Author to whom correspondence should be addressed; E-Mail: patrick.schweighofer@campus02.at; Tel.: +43-316-6002 (ext. 344); Fax: +43-316-6002-1222.

Academic Editor: Igor V. Tetko

Received: 8 October 2014 / Accepted: 7 January 2015 / Published: 3 February 2015

\begin{abstract}
The significance of approaches to technology-enhanced learning (TEL) has increased rapidly during the last few years. Nowadays in education different approaches such as game-based learning, web-based learning, video-based online courses, and many others are used on a daily basis. However, what defines the success of technology-enhanced learning approaches and how can such approaches be developed in a structured way? Furthermore, what different aspects have to be considered while doing so? To answer these questions, 4567 publications were analyzed in this present literature review in order to recognize the different aspects of implementing technology-enhanced learning approaches. Finally, 20 categories are defined in four main areas that summarize all the aspects in the field of technology-enhanced learning. Moreover, the study also reveals research areas that are important but hardly investigated in the observed journals of this study.
\end{abstract}

Keywords: technology-enhanced learning; online learning; e-learning; research fields 


\section{Introduction}

The use of various technologies to enhance education, the field of technology-enhanced learning (TEL), is nowadays widespread. The motivations for this progress are manifold. For instance, Schweighofer, Grünwald, and Ebner [1] identified in a literature review several publications that give reasons for the necessity of technology-enhanced learning approaches. On the whole, the identified publications claim that these approaches are required for living and working in our digital economy, and since people are used to using technologies in their life, they demand learning scenarios that apply those technologies.

The term technology-enhanced learning itself is the most widespread term in this field and combines all approaches in which technology is used to support the learning or teaching process. Thus, terms like e-learning and online learning, as well as more specialized fields such as game-based learning, web-based learning, and others, are part of the research field of technology-enhanced learning [2].

This definition of the term technology-enhanced learning also implies that the research area is vast, and when successfully implementing technology-enhanced learning approaches different aspects have to be considered. However, there are only a few methodologies that support this structured development of individual and successful approaches. In the following, selected methodologies and the aspects addressed in these methodologies are described briefly.

Fink, Gabriel, Gersch, Lehr, and Weber [3] address the issue as learn service engineering. They suggest that technology-enhanced learning approaches should be treated as services. In this way a structured development, comparable to the engineering discipline of service engineering [4], is possible. In doing so, Fink et al. [3] consider four main views: economic aspects, technical aspects, didactic aspects, and general organizational conditions.

Another generic methodology looks especially at the development process itself and considers the four stages of planning, implementing, controlling, and improving, whereby learning outcomes are used as control variables [5], and an even more generic model observes pedagogical, social, and technological perspectives [6].

The issue of the structured development of e- and m-learning was also considered within the Europe-wide project UNITE. In the project, a pedagogical framework was evaluated that considers five components: pedagogical framework context, pedagogical approaches, assessment techniques, current pedagogical practices implemented in national curricula and national specifics, and teacher training [7].

Alonso, Manrique, and Viñes [8] show a more detailed model to develop effective e-learning for teaching a coding language. First, they divide the process into five phases: analysis, design, implementation, execution, and evaluation. Second, during each phase they consider the following aspects: perception, attention, cognitive load, coding, retrieval/transfer, and metacognition.

Furthermore, focused on the development of online learning programs and to determine their success, Rovai and Downey [9] suggest taking seven important factors into account: planning, marketing and recruitment, financial management, quality assurance, student retention, faculty development, and online course design and pedagogy.

As can be seen, the considered aspects in these models are not unified and none of the above methodologies include all possible facets that are investigated in the research field of technology-enhanced learning. This led to the following research question: 
What aspects could possibly be considered when implementing technology-enhanced learning approaches?

The answer to this question is given by a large-scale literature review identifying aspects examined in the research area of technology-enhanced learning that could be considered when implementing approaches to TEL. Finally, at the end of this paper, based on the result of the literature review a new generic and holistic model that illustrates the identified aspects in a cluster is suggested.

\section{Research Method}

The research method used here is based on the method used by $\mathrm{Wu}$, Chiou, $\mathrm{Kao}, \mathrm{Hu}$, and Huang [10] in their literature review about game-assisted learning. The method thus consists of the following steps: defining technology-enhanced learning, defining inclusion/exclusion criteria, defining data sources and search strategies, and performing data analysis.

\subsection{Definition of Technology-Enhanced Learning}

To fulfill the purpose of this study, the term technology-enhanced learning is defined as the collection of all approaches in which technology is used to support the learning or teaching process [2]. Based on this definition, the study is not limited to a special field of technology-enhanced learning. Web-based learning or game-based learning are addressed within this study as well as computer-based learning environments, the simple usage of animations or computer generated pictures and movies, and all other possible ways to use technology to enhance the learning or teaching process.

\subsection{Inclusion/Exclusion Criteria}

The inclusion/exclusion criteria for publications to be part of this study are as follows:

- The publication has to have a relation to the field of technology-enhanced learning as it is defined for the purpose of this study.

- The purpose of the publication has to address one or more aspects that could possibly be considered when implementing technology-enhanced learning approaches. Publications that introduce new approaches in the field of technology-enhanced learning without explicitly addressing one or more aspects are not taken into account.

- The publication has to be published between 2009 and 2014 (request date November 2013).

- The publication has to be downloadable in full-text at our home university.

- The publication has to be in English.

\subsection{Data Sources and Search Strategies}

Due to the research purpose - finding aspects which could possibly be considered when implementing approaches to TEL - a search strategy based on search terms alone is not suitable, since it would limit the range of aspects to the selected search terms. Instead, in two major bibliographic databases all publications of high-ranked journals in the area of education are analyzed, to ensure that a wide area of possible aspects is considered and there are no limitations caused by selected search terms. The two databases used are SCOPUS and Web of Knowledge. In Web of Knowledge all journals from the 
category education \& educational research with a five-year impact factor greater than 1.5 (based on the 2012 JCR Social Sciences Edition) and in SCOPUS all journals with "education", "learning”, or "teaching" in the journal title, excluding journals about machine learning, with a SCImago Journal Rank greater than 1.0 are taken into account. Finally, only journals that provide full-text download and are accessible at our home university are part of the review. Altogether, 12 journals with a total of 4567 publications are initially considered in this study.

\subsection{Data Analysis}

Out of these 4567 publications, a total of 412 studied at least one aspect that could be considered when implementing technology-enhanced learning approaches. During the analysis these aspects were collected, clustered, and verified once more for quality assurance. The clustering itself as well as the definition of hypernyms was not restricted to using existing models but is strictly based on similarity of the identified aspects in the publications. In detail the following steps lead to the final categorization:

(1) Collecting: Based on the publications' research question and purpose, the terms for aspects that could possibly be considered when implementing approaches to TEL as they are used in the publications are collected.

(2) Ordering: The collected original terms are ordered in a way based on similarity.

(3) Defining: Hypernyms for similar terms are defined.

(4) Assigning: The publications are assigned to the defined hypernyms.

The following example represents the process that has taken place for the category "mind-set and feelings before TEL". This category contains all aspects that address beliefs, conceptions, or expectations before technology-enhanced learning approaches are implemented or used:

(1) Collecting: The analyzed publications studied the following aspects: beliefs, students' beliefs, teachers' beliefs, estimated potential for learning contribution, students' conceptions of technology-enhanced learning, students' conceptions, students' expectations, teachers' expectations, and technological expectancy. In so doing, for instance, these aspects are collected due to following phrases out of the publications (note: some of the listed phrases contain other aspects as well and are therefore not only counted in the category "mind-set and feelings before TEL"):

(a) beliefs: "The aim of this study is to investigate the complexity of past experiences with ICT, pedagogical beliefs, and attitude toward ICT in education that the Net Generation student teachers have about their intention to teach and learn with technology. " [11]

(b) students' beliefs: "The purpose of the study was to explore possible links between student socioeconomic status (SES), beliefs about information and communication technologies (ICTS), and out-of-school learning resources. " [12]

(c) teachers' beliefs: "This study was conducted to explore the relationships between teachers' motivation toward web-based professional development, Internet self-efficacy, and beliefs about web-based learning. " [13]

(d) estimated potential for learning contribution: "This study aims at critically reviewing recently published scientific literature on the use of computer and video games in Health Education (HE) and Physical Education (PE) with a view: (a) to identifying the potential 
contribution of the incorporation of electronic games as educational tools into HE and PE programs, [...]'"[14]

(e) conceptions of technology enhanced learning of students: "The present study investigated junior college students' conceptions of and approaches to learning via online peer assessment (PA) using a phenomenographic approach. " [15]

(f) students' conceptions: "By interviewing 83 Taiwanese college students with some web-based learning experiences, this study attempted to investigate the students' conceptions of learning, conceptions of web-based learning, and the differences between these conceptions." [16]

(g) students' expectations: "Multiple regression analyses using Mplus 4.21 were carried out to investigate how different facets of students' expectations and experiences are related to perceived learning achievements and course satisfaction." [17]

(h) teachers' expectations: "This exploratory case study examined pre-service teachers' expectations of and attitudes toward the learning and integrating of ICT into their teaching, and their perceptions of the availability and use of ICT in the Teacher Education Program (TEP) and their placement schools." [18]

(i) technological expectancy: "Thus, researchers should take into consideration both technological and learning expectancies of students while investigating e-learning acceptance." [19]

(2) Ordering: The identified terms are ordered in a way based on similarity as follows:

(a) beliefs, students' beliefs, teachers' beliefs, estimated potential for learning contribution

(b) conceptions of technology enhanced learning of students, students' conceptions

(c) students' expectations, teachers' expectations, technological expectancy

(3) Defining: The following hypernyms for the ordered terms are defined:

(a) beliefs: beliefs, students' beliefs, teachers' beliefs, estimated potential for learning contribution

(b) conceptions: conceptions of technology enhanced learning of students, students' conceptions

(c) expectations: students' expectations, teachers' expectations, technological expectancy

(4) Defining: The following hypernym for the category is defined:

(a) mindset and feelings before TEL: beliefs, conceptions, expectations

(5) Assigning: The analyzed publications are assigned to the new defined hypernym(s).

The chosen method for identifying relevant aspects covers a wide area. To achieve such a broad database is the main purpose of the chosen method since journals with a technology-enhanced learning focus cover different aspects as do journals that, for example, specialize in psychology, science, or teaching. However, it has to be said that this method has limitations as well; hence, relevant publications not found by the two databases are excluded from this study, as are publications from other journals.

\section{Literature Review}

The identified aspects that could be considered when implementing technology-enhanced learning approaches are clustered into 20 categories. Each category consists of aspects that show a high similarity. 
For example, in the category "demographic differences" all aspects regarding the learners' general circumstances, like the learners' age and cultural background, are taken together.

The following sections briefly describe the content of the identified categories. Additionally, to provide better insight, reviews of selected publications from the categories are given. However, it is not the aim of this publication to discuss the methods used and results of the identified publications in detail but rather to identify the investigated aspects in the analyzed publications.

An overview of the identified categories of aspects considered in the journals can be seen in Table 1 . Additionally, the table shows the number of analyzed articles in the journal and how many of them involved aspects that can be considered (added to journal in parenthesis). Table 2 shows the identified categories of aspects per year. Both tables are ordered alphabetically. Since most publications explored more than one aspect, often from different categories, the total number of identified aspects is higher than the number of publications.

\subsection{Acceptance Aspects}

Investigating the acceptance of technology-enhanced learning approaches or technology itself is wide-spread. This category, therefore, combines all publications dealing with aspects of acceptance regarding online learning, web-based learning, game-based learning, technology-enhanced learning, learning environments, and technology usage. The publications here not only address the acceptance of learners, but also the acceptance of teachers and other involved parties, such as parents. In total, 36 publications address aspects of acceptance.

For instance, Bourgonjon, Valcke, Soetaert, de Wever, and Schellens [20] studied the reasons why parents often have negative perceptions - especially towards game-based learning. They claim that the missing acceptance of parents often has a negative influence on teachers, students, and policy makers and is therefore a barrier for game-based learning scenarios. Furthermore, they show a hypothetical path model in their work that helps to explain and predict parental acceptance.

Regarding teachers' acceptance, Pynoo et al. [21] use two sources to determine whether teachers accept educational portals or not. Firstly, they analyze the amount of usage. For example, the number of logins, downloads, uploads, reactions, and pages viewed. Secondly, they use an online questionnaire. The results of two surveys, 22 months apart, show that attitude and perceived usefulness are the strongest predictors of behavioral intention.

A well-known model to determine the acceptance of technology is the technology acceptance model. In their work, Chow, Herold, Choo, and Chan [22] show how they use this model to evaluate the learners' acceptance of a learning scenario in the virtual environment Second Life.

\subsection{Business Aspects}

Altogether, 38 articles cover business aspects of technology-enhanced learning. These studies mainly address the holistic effectiveness and efficiency of technology-enhanced learning approaches. Furthermore, the value and benefits as well as difficulties and organizational influences are considered. Finally, a few works investigate cost reduction, quality assurance, and ethical dimensions. 
Table 1. Identified categories of aspects per journal.

\begin{tabular}{|c|c|c|c|c|c|c|c|c|c|c|c|c|c|}
\hline $\begin{array}{r}\text { Journal (analyzed } \\
\text { articles/ } \\
\text { taken articles) }\end{array}$ & $\begin{array}{c}\text { Computers } \\
\& \\
\text { education } \\
\text { (1201/253) }\end{array}$ & $\begin{array}{c}\text { Contemporary } \\
\text { educational } \\
\text { psychology } \\
\text { (149/3) }\end{array}$ & $\begin{array}{c}\text { Early } \\
\text { childhood } \\
\text { research } \\
\text { quarterly } \\
(235 / 1)\end{array}$ & $\begin{array}{c}\text { Economic } \\
\text { s of } \\
\text { education } \\
\text { review } \\
(484 / 1)\end{array}$ & $\begin{array}{c}\text { Educational } \\
\text { research } \\
\text { review } \\
(87 / 3)\end{array}$ & $\begin{array}{c}\text { Interactive } \\
\text { learning } \\
\text { environments } \\
\text { (150/52) }\end{array}$ & $\begin{array}{c}\text { Internet } \\
\text { and higher } \\
\text { education } \\
\text { (167/47) }\end{array}$ & $\begin{array}{c}\text { Journal of } \\
\text { research in } \\
\text { science } \\
\text { teaching } \\
(273 / 3)\end{array}$ & $\begin{array}{c}\text { Learning } \\
\text { and } \\
\text { instruction } \\
(253 / 30)\end{array}$ & $\begin{array}{l}\text { Physical review } \\
\text { special } \\
\text { topics—physics } \\
\text { education } \\
\text { research } \\
(172 / 7) \\
\end{array}$ & $\begin{array}{c}\text { Science \& } \\
\text { education } \\
(713 / 0)\end{array}$ & $\begin{array}{c}\text { Teaching } \\
\text { and teacher } \\
\text { education } \\
(683 / 12)\end{array}$ & $\begin{array}{c}\text { Count } \\
\text { (4567/412) }\end{array}$ \\
\hline Acceptance aspects & 31 & - & - & - & - & 4 & 1 & - & - & - & - & - & 36 \\
\hline Business aspects & 21 & - & - & - & - & 13 & 2 & - & 1 & - & - & 1 & 38 \\
\hline Cognitive aspects & 22 & 1 & - & - & - & 6 & 1 & - & 9 & - & - & - & 39 \\
\hline Course-related aspects & 6 & - & - & - & - & 1 & 5 & - & - & - & - & 1 & 13 \\
\hline Demographic differences & 21 & - & - & - & - & 1 & 5 & - & - & - & - & - & 27 \\
\hline $\begin{array}{c}\text { Influences from prior knowledge } \\
\text { and experience } \\
\end{array}$ & 23 & - & - & - & - & 5 & 8 & - & 1 & - & - & 2 & 39 \\
\hline Instruction aspects & 6 & - & - & - & - & 6 & 3 & 1 & 3 & - & - & 1 & 20 \\
\hline Learners' learning aspects & 62 & 1 & - & - & 2 & 19 & 10 & - & 7 & 1 & - & - & 102 \\
\hline Learners' requirements & 16 & - & - & - & - & 4 & 4 & - & - & - & - & - & 24 \\
\hline Learning success & 117 & 3 & 1 & 1 & 2 & 20 & 14 & 3 & 17 & 7 & - & 1 & 186 \\
\hline Mind-set \& feelings before TEL & 15 & - & - & - & - & - & 2 & - & 1 & - & - & 5 & 23 \\
\hline Mind-set \& feelings during TEL & 67 & - & - & - & - & 7 & 26 & - & 1 & - & - & 1 & 102 \\
\hline Motivational aspects & 52 & - & - & - & - & 8 & 10 & - & 2 & - & - & 2 & 74 \\
\hline Requirements on teachers & - & - & - & - & - & - & - & - & - & - & - & 3 & 3 \\
\hline Self-regulation aspects & 23 & 1 & - & - & - & 3 & 7 & - & 2 & - & - & - & 36 \\
\hline Social aspects & 3 & - & - & - & - & - & - & - & 1 & - & - & - & 4 \\
\hline Support processes & 14 & - & - & - & - & 4 & 1 & - & 8 & - & - & - & 27 \\
\hline Teachers' teaching aspects & 9 & - & - & - & - & 1 & - & - & - & - & - & 2 & 12 \\
\hline Technical infrastructure aspects & 7 & - & - & - & - & 2 & 6 & - & 2 & - & - & 1 & 18 \\
\hline Technology-related aspects & 20 & - & - & - & - & 1 & 3 & - & 1 & - & - & 5 & 30 \\
\hline Count & 535 & 6 & 1 & 1 & 4 & 105 & 108 & 4 & 56 & 8 & $\mathbf{0}$ & 25 & 853 \\
\hline
\end{tabular}


Table 2. Identified categories of aspects per year of publication.

\begin{tabular}{lcccccccc}
\hline \multicolumn{1}{c}{ Year of publication } & $\mathbf{2 0 0 9}$ & $\mathbf{2 0 1 0}$ & $\mathbf{2 0 1 1}$ & $\mathbf{2 0 1 2}$ & $\mathbf{2 0 1 3}$ & $\mathbf{2 0 1 4}$ & Count \\
\hline Category & 10 & 4 & 7 & 9 & 6 & - & $\mathbf{3 6}$ \\
Busceptance aspects & 7 & 10 & 6 & 11 & 4 & - & $\mathbf{3 8}$ \\
Cognitive aspects & 8 & 10 & 6 & 8 & 7 & - & $\mathbf{3 9}$ \\
Course-related aspects & 4 & 3 & 3 & 2 & 1 & - & $\mathbf{1 3}$ \\
Demographic differences & 6 & 6 & 5 & 3 & 7 & - & $\mathbf{2 7}$ \\
Influences from prior knowledge and experience & 7 & 5 & 12 & 9 & 6 & - & $\mathbf{3 9}$ \\
Instruction aspects & 3 & 8 & 2 & 3 & 4 & - & $\mathbf{2 0}$ \\
Learners' learning aspects & 20 & 25 & 15 & 26 & 15 & 1 & $\mathbf{1 0 2}$ \\
Learners' requirements & 3 & 6 & 6 & 5 & 4 & - & $\mathbf{2 4}$ \\
Learning success & 44 & 40 & 28 & 37 & 37 & - & $\mathbf{1 8 6}$ \\
Mind-set \& feelings before TEL & 6 & 4 & 2 & 3 & 8 & - & $\mathbf{2 3}$ \\
Mind-set \& feelings during TEL & 14 & 21 & 19 & 23 & 25 & - & $\mathbf{1 0 2}$ \\
Motivational aspects & 17 & 17 & 12 & 12 & 16 & - & $\mathbf{7 4}$ \\
Requirements on teachers & - & 2 & - & - & 1 & - & $\mathbf{3}$ \\
Self-regulation aspects & 8 & 9 & 7 & 3 & 9 & - & $\mathbf{3 6}$ \\
Social aspects & 2 & 1 & - & 1 & - & - & $\mathbf{4}$ \\
Support processes & 3 & 6 & 6 & 6 & 6 & - & $\mathbf{2 7}$ \\
Teachers' teaching aspects & 2 & 3 & 3 & 3 & 1 & - & $\mathbf{1 2}$ \\
Technical infrastructure aspects & 7 & 3 & 5 & 3 & - & - & $\mathbf{1 8}$ \\
Technology-related aspects & 5 & 3 & 6 & 6 & 10 & - & $\mathbf{3 0}$ \\
\hline Count & $\mathbf{1 7 6}$ & $\mathbf{1 8 6}$ & $\mathbf{1 5 0}$ & $\mathbf{1 7 3}$ & $\mathbf{1 6 7}$ & $\mathbf{1}$ & $\mathbf{8 5 3}$ \\
\hline
\end{tabular}

Regarding cost reduction, Ho and Dzeng [23] show in their study about safety training via online learning in enterprises, among other aspects, how much enterprises can save by using online learning scenarios to train their staff. However, their study cannot clarify a mutual relationship between the costs and effectiveness of online learning.

With qualitative and quantitative methods, Czerniewicz and Brown [24] examine the organizational influence of policies and culture on online learning in four South African universities. Their results show a relationship between policies and the use of technology for teaching and learning. Furthermore, the results confirmed a crucial relationship between organizational culture and the importance and usage of online learning in the observed universities.

T. Wang [25], for example, investigates the general benefits and difficulties of implementing technologies to enhance architectural education. Among others, T. Wang sees one difficulty in the fact that both learners and teachers have to learn how to use technology-enhanced learning approaches effectively before any benefits can be achieved. On the other hand, T. Wang also mentions the benefits of technology-enhanced learning approaches, especially when it comes to lifelong learning.

\subsection{Cognitive Aspects}

In this category, cognitive aspects such as cognitive load, cognitive abilities, cognitive processes, and aspects regarding learners' attention are combined. Out of the analyzed publications, 39 deal with these aspects. 
For example, Austin [26] studies the effect of individual cognitive differences on performance. In detail, her study deals with the impact of multimedia combinations, and the results show that display design influences the attention and cognitive load.

Annetta, Minogue, Holmes, and Cheng [27] evaluated in their study the cognitive impact on students while playing a teacher-created video game. Their study shows that although no effect on learning outcomes could be measured, the influence on the participants' level of engagement was significant.

A way to track and explore learners' attention is shown by Boucheix and Lowe [28]. They used eye tracking to investigate learners' attention in learning scenarios with complex animations within two experiments.

\subsection{Course-Related Aspects}

Course-related aspects are aspects regarding the course design, the delivery mode used, the time provided for individual tasks, the purpose or the teaching discipline itself, and the relevance of the course for the learners. In this study, 13 publications are identified that deal with such aspects.

One of these 13 articles researches the effects on the development of a community of inquiry when providing different time periods. In detail, the effects were measured on a single course, which was held by the same teacher for 13 weeks or six weeks. The results of the study mainly show differences in the development of cognitive presence [29].

Moreover, in a literature review Arbaugh et al. [30] detected that the volume and quality of online and blended learning approaches differ regarding the teaching discipline. In detail, approaches in business disciplines are part of the review and the results show that in subjects such as Finance and Economics there are only a few online or blended learning approaches implemented.

Klašnja-Milićević, Vesin, Ivanović, and Budimac [31] present a recommendation module of a programming tutoring system called Protus in their work. Among other aspects, the system recommends learning content based on the relevance for students.

\subsection{Demographic Differences}

The category "demographic differences" covers all aspects regarding learners' age, cultural and ethnic background, socioeconomic status and general background, as well as gender differences. In total, 27 publications are identified that investigate the impact of demographic differences on several aspects of technology-enhanced learning.

Ke and Kwak [32], for instance, examine in their study the relationship between learners' age and ethnic background to their participation, interaction, perceptions, and learning satisfaction in online courses. In detail, they collected data from students enrolled in 28 online courses.

Additionally, the effects of national and cultural background on technology acceptance are studied by Sánchez-Franco, Martínez-López, and Martín-Velicia [33].

Regarding the impact of gender differences on learning satisfaction, for example, González-Gómez, Guardiola, Rodríguez, and Alonso [34] provide evidence that female students are more satisfied with online learning than male students. 


\subsection{Influences from Prior Knowledge and Experience}

In total, 39 publications consider influences from prior knowledge and experiences on technology-enhanced learning approaches. Here, the digital competence of learners and teachers, the learners' knowledge levels, and their prior experiences with technology-enhanced learning scenarios are treated.

Paechter, Maier, and Macher [17] investigate the impact of learners' prior experiences on learning achievements and learning satisfaction in their study of 2196 students form 29 universities. The results show that students' learning satisfaction and learning achievements within online courses depend highly on the teachers' usage of the technology learning approach and the given support during the online course.

In another study Park, Lee, and Kim [35] observed, among other aspects, the influence of the students' prior knowledge level on concept comprehension, cognitive load, and learning efficiency. In detail, their study shows a positive impact on these variables by using high-interactive simulations if the learners' prior knowledge level is high.

Finally, regarding the digital competence of learners, the term "digital natives" is widespread. However, Margaryan, Littlejohn, and Vojt [36], for instance, show in their study that young people, so-called digital natives, only differ quantitatively but not qualitatively in their technology usage during learning.

\subsection{Instruction Aspects}

Twenty publications out of the 4567 articles analyzed cover instruction aspects in their research. In them the influence of instructions and the impact of different instructional designs and strategies, as well as instructions' effectiveness, are dealt with.

For instance, Inan, Lowther, Ross, and Strahl [37] identified in their work different instructional strategies used by teachers in technology-enhanced learning approaches. Their work shows that in most cases technology is not used for instructional delivery but as a learning tool.

In their study dealing with instructional strategies, Borup, West, and Graham [38] compared different video-based instructions. Their results show that video-based instructions are similar to face-to-face instructions from a student's point of view.

Concerning instruction effectiveness, especially in virtual worlds, Mayrath, Traphagan, Heikes, and Trivedi [39] show lessons learned based on a case study which integrated Second Life into an English course.

\subsection{Learners' Learning Aspects}

This category combines all aspects regarding the learners' learning, meaning all publications that address other aspects such as learning behavior and process and learning strategy and style, as well as interaction and participation. In total, 102 publications investigate learners' learning aspects.

Falloon [40] observes the impact of using iPads in learning scenarios for five-year-old students on learning pathways. The results identify several determining factors. 
Participation and interaction is also a very important aspect. Oliveira, Tinoca, and Pereira [41] examine the different types of collaborative practices, especially in discussion forums. In summary, their results show that distinct work patterns have influences on the learning outcomes.

Finally, Latham, Crockett, McLean, and Edmonds [42] propose a conversational intelligent tutoring system, which adapts itself to the learners' learning style. They claim that learning experience and effectiveness will be improved by this.

\subsection{Learners' Requirements}

Additionally to learners' learning aspects in this category, their requirements are covered. In all there are 24 identified articles that investigate the demands and preferences learners have in a technology-enhanced learning environment. Furthermore, publications addressing the learners' readiness for learning and using technology are also part of this category.

For example, Darab and Montazer [43] explore whether students are ready for online learning scenarios. They conducted a survey that identified existing capabilities and deficits.

Concerning learners' preferences, a survey by Lawlor and Donnelly [44] observed what kind of podcast formats learners prefer. Their results show that a mixture of key-point slides and explanatory voice-over corresponds best to learners' preferences.

Another issue regarding learners' demands addresses the identity in online learning systems. Yu and $\mathrm{Wu}$ [45] examine preferences regarding the following four different identity revelation modes: always showing the real name, always showing a nickname, always being anonymous, and deciding in each situation between real name, nickname, and anonymity.

\subsection{Learning Success}

Most of the 4567 analyzed publications - in particular, 186 - deal with aspects regarding learning success. The articles address, among other aspects, learning effectiveness, learning efficiency, learning quality, and learning performance.

Representatively, in their work Eow, Ali, Mahmud, and Baki [46] study the relation between learning achievements and the time students spend playing computer games. However, their findings only show weak relations.

Furthermore, concerning game-based learning, Hong, Tsai, Ho, Hwang, and Wu [47] observe in their study that game-based learning is more effective for boys than it is for girls. The result is based on an experiment with a developed embodied interactive video game.

Kim, Hong, Bonk, and Lim [48] show in their work how team learning outcomes are influenced by Web 2.0 environments. However, they additionally claim that collective reflection and critical thinking are even more important.

\subsection{Mindset and Feelings before TEL}

The category "mindset and feelings before TEL" covers all publications - in detail 23 were identified - that address aspects such as beliefs, conceptions, and expectations before technology-enhanced learning approaches are implemented or used. 
For instance, Prestridge [49] investigates how teachers' beliefs influence their usage of technology in learning scenarios. The findings are based on interviews, surveys and document analysis.

Terzis, Moridis and Economides [50] observe the other side, namely the learners' expectations in their study. Their work includes a study of the influences of learners' expectations on their acceptance of computer based assessment without limitation.

Tsai [16] shows differences between students' conceptions of learning and web-based learning. The study is based on interviewing 83 Taiwanese college students. The results show that conceptions regarding web-based learning are often more sophisticated.

\subsection{Mindset and Feelings during TEL}

In comparison to the category "mindset and feelings before TEL", this category addresses aspects such as attitude, perceptions, perspectives, satisfaction, and emotions during the usage of technology-enhanced learning approaches. One hundred and two publications are identified that investigate these aspects.

Şad [51], for instance, postulates an instrument to measure students' attitudes towards the usage of smart boards in education. The instrument is called Smart Board Attitude Scale and asks, among other questions, about the students' enjoyment or their willingness to go to school because of the smart board lessons.

Dziuban, Moskal, Kramer, and Thompson [52] also consider students' satisfaction, in their case concerning online courses. They also provide an instrument to measure students' satisfaction that addresses, inter alia, the stimulation of interest, the pace, and feedback given.

Concerning teachers' feelings during the usage of technology in their learning scenarios, Regan et al. [53] show in their work the results of a qualitative study regarding teachers' emotions while teaching in an online learning environment.

\subsection{Motivational Aspects}

Seventy-four publications out of the 4567 analyzed investigate motivational aspects, such as intention, engagement, and self-efficacy. The articles address learners' motivation as well as teachers' motivations.

Teo [54] presents a model which explains teachers' intention to use technology in learning scenarios. The model addresses perceived usefulness, perceived ease of use, subjective norm, facilitating conditions, and attitude towards use, as well as the behavioral intention.

Regarding students' motivation, Deng and Tavares [55] examine in a qualitative study motivating and inhibiting factors that have influence on students' engagement in online discussions. Their results show that, among other factors, the technical tools used, subjective perceptions, and rules for participation affect the students' engagement.

Chatzoglou, Sarigiannidis, Vraimaki, and Diamantidis [56] address the intentions of employees in organizations to use web-based training scenarios. They thus extend the technology acceptance model with factors like management support, enjoyment, and self-efficacy. 


\subsection{Requirements on Teachers}

Merely three publications, the smallest number of articles in any category, deal with requirements on teachers. All of them are identified in the journal Teaching and Teacher Education.

Firstly, Guasch, Alvarez, and Espasa [57] investigate what requirements there are on university teachers for teaching in virtual learning environments.

Secondly, Han, Eom, and Shin [58] in particular cover the issue of how teachers can improve their technological and pedagogical knowledge to use technology in their teaching, and how later knowledge integration can be improved.

Finally, Polly, Mims, Shepherd, and Inan [59] also address requirements on teachers for using technology in their teaching by analyzing the findings of several projects of an U.S. initiative. For this they use the framework of technological pedagogical content knowledge.

\subsection{Self-Regulation Aspects}

Self-regulation aspects go to form the research purpose of 36 identified publications. Self-regulated learning, meaning flexibility regarding pace and order, the learning effort spent, and time management, as well as computer and Internet self-efficacy, are among the examined aspects.

Fulton, Ivanitskaya, Bastian, and Erofeev [60] show relations between learners' control over pace and their learning performance in an experiment. In their experiment, they compared two groups with weekly deadlines and monthly deadlines. The results show that students with less control over pace have a better learning performance.

Hodges and Murphy [61] also investigate learners' self-efficacy in an asynchronous, technology-intensive mathematics course. However, they focused more on the learners' self-efficacy beliefs.

Finally, Shen, Cho, Tsai, and Marra [62] identified five dimensions of online learning self-efficacy in their work. These dimensions are: self-efficacy to complete an online course, self-efficacy to interact socially with classmates, self-efficacy to handle tools in a Course Management System, self-efficacy to interact with instructors in an online course, and self-efficacy to interact with classmates for academic purposes.

\subsection{Social Aspects}

Only four publications, the second smallest number of articles in a category, deal directly with social aspects such as social behavior and competences.

In their study, Krause, Stark, and Mandl [63] examine the influence of the social context-individual $v s$. cooperative learning - as well as feedback intervention on learning outcomes. Their results show, among other things, that group learning especially increases the perceived learning performance and learning outcomes.

Furthermore, Pérez-Mateo and Guitert [64] investigate social expression. In their work they propose indicators that are categorized as formal, attitudinal, emotional, and informal.

A special issue is addressed by Cheng and Ye [65]. They use a virtual learning environment, which should help to increase the social competences and interaction of people with autism spectrum conditions. 


\subsection{Support Processes}

Aspects of support processes are part of 27 identified articles. The articles deal with issues like feedback, learning monitoring, and help-seeking, as well as helping processes.

Jara and Mellar [66] observe the aspect of feedback. In detail, they study how students' feedback to online learning courses can be used for quality assurance.

De Wever, Van Keer, Schellens, and Valcke [67] compare the differences in learning outcomes between tutor-supported online discussions and role-supported online discussions. Their results show that the level of knowledge acquisition is higher in the tutor-supported group.

Additionally, Mäkitalo-Siegl and Fischer [68] give an overview of the research field of help-seeking processes.

\subsection{Teachers' Teaching Aspects}

The category "teachers' teaching aspects" covers issues like the teaching style, teachers' behavior, teachers' self-reflection, the teaching performance, and the teaching strategy. In all, 12 of the 4567 analyzed articles investigate such aspects.

For instance, in their experiment, Chen, Kinshuk, Wei, and Liu [69] analyze the influence of teaching strategies that are suited to different learning styles on the learning outcomes. The experiment covers three teaching strategies that are suited to three thinking styles.

A similar experiment is conducted by Hsieh, Jang, Hwang, and Chen [70]. They also observe the influence of teaching styles and learning styles - in their case regarding ubiquitous learning.

Regarding web-based digital video, Krauskopf, Zahn, and Hesse [71] study in particular the teaching style necessary when teaching using digital videos.

\subsection{Technical Infrastructure Aspects}

In all, 18 publications are identified that address technical infrastructure aspects. The accessibility of the technical infrastructure, reliability, and aspects regarding the learning environment, such as usability, among other things, are addressed.

Regarding the technical infrastructure, Seufert, Schütze, and Brünken [72] observe in two experimental studies the impact of different presentation possibilities in a multimedia learning environment.

Furthermore, Lehman, D’Mello, and Graesser [73] claim that confusion can increase learning outcomes because confusion can provide opportunities for deep learning. They investigate here four computer learning environments that cause confusion in learners' minds.

Liang and Sedig [74] also address aspects concerning the learning environment. In their study, they observe the navigation process in interactive learning environments and propose a framework that helps with designing an interactive learning environment in order to avoid difficulties with searching for information in the learning environment. 


\subsection{Technology-Related Aspects}

The last category covers technology-related aspects. In total, 30 publications address such aspects. Specifically, the publications address two issues: the process of integrating technology and the usage of technology in learning and teaching scenarios.

For instance, Ketelhut and Schifter [75] propose in their work a theoretical model that helps to integrate technology in learning scenarios, especially those concerning game-based learning.

Furthermore, Peeraer and Van Petegem [76] describe in their publication a questionnaire to measure the integration of technology in education.

On the other hand, in a survey of over 1000 learners, Eynon and Malmberg [77] observe how young people use the Internet in non-educational settings. Based on the results, they suggest how to use the Internet to enhance learning and education.

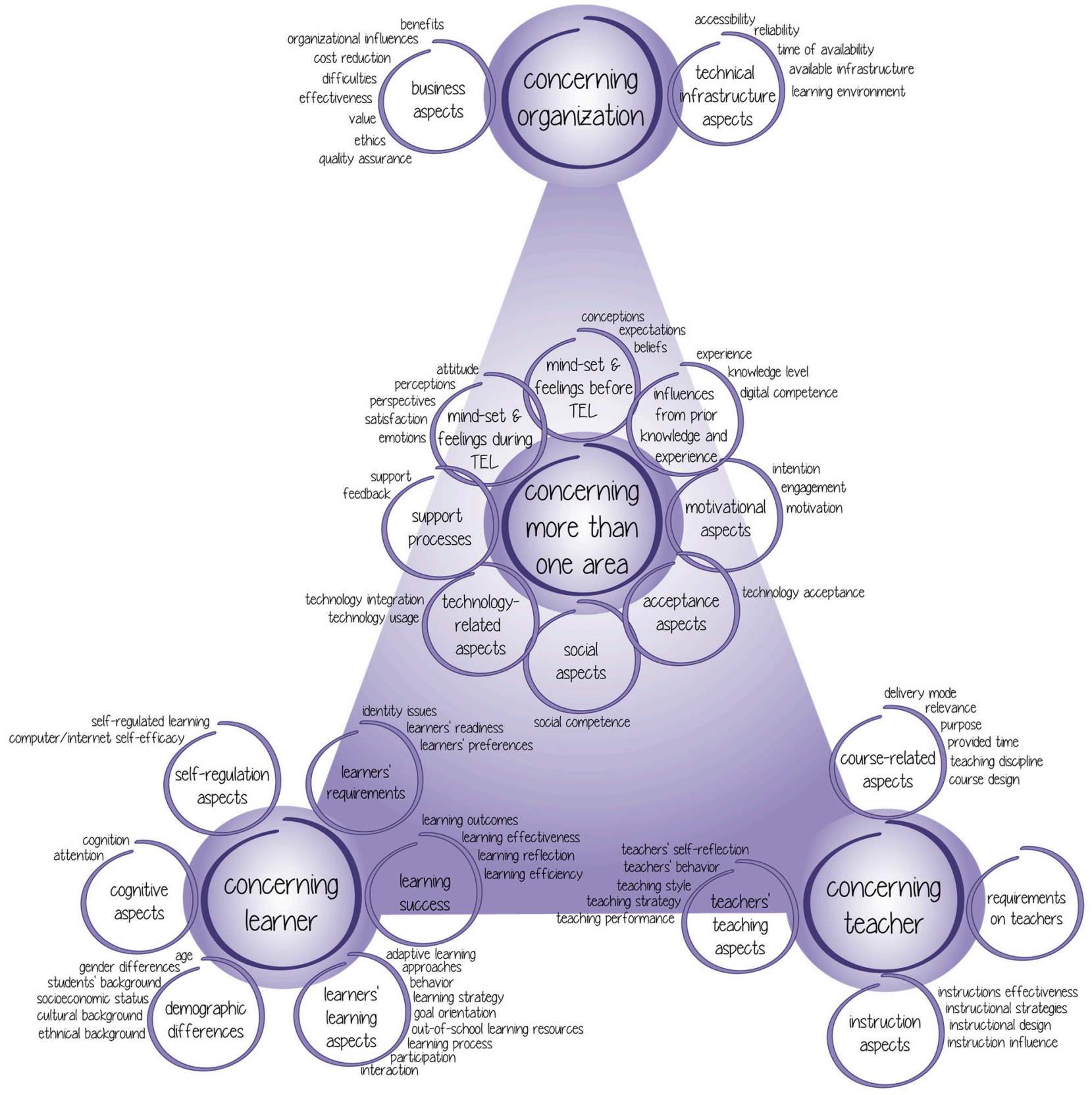

Figure 1. Model of aspects that can be considered when implementing TEL approaches. 


\subsection{Overview of Aspects that Can Be Considered}

All in all, the literature review identified 20 categories and 76 subcategories. Figure 1 shows these identified categories and sub categories. Additionally, the figure shows that the categories can be divided into four main areas based on the addressed stakeholders in the category. A category can thus concern the organization, the learner, the teacher, or more than one of these areas.

Summarized, Figure 1 shows all aspects that could possibly be considered when implementing technology-enhanced learning approaches based on current research purposes. A category dealing with the technological development of new technology-enhanced learning approaches is missing in the figure, since all publications that introduce new approaches in the field of technology-enhanced learning without explicitly addressing one or more aspects are not taken into account. However, while planning and developing new approaches to TEL, the aspect of the technological development of course has to be considered too.

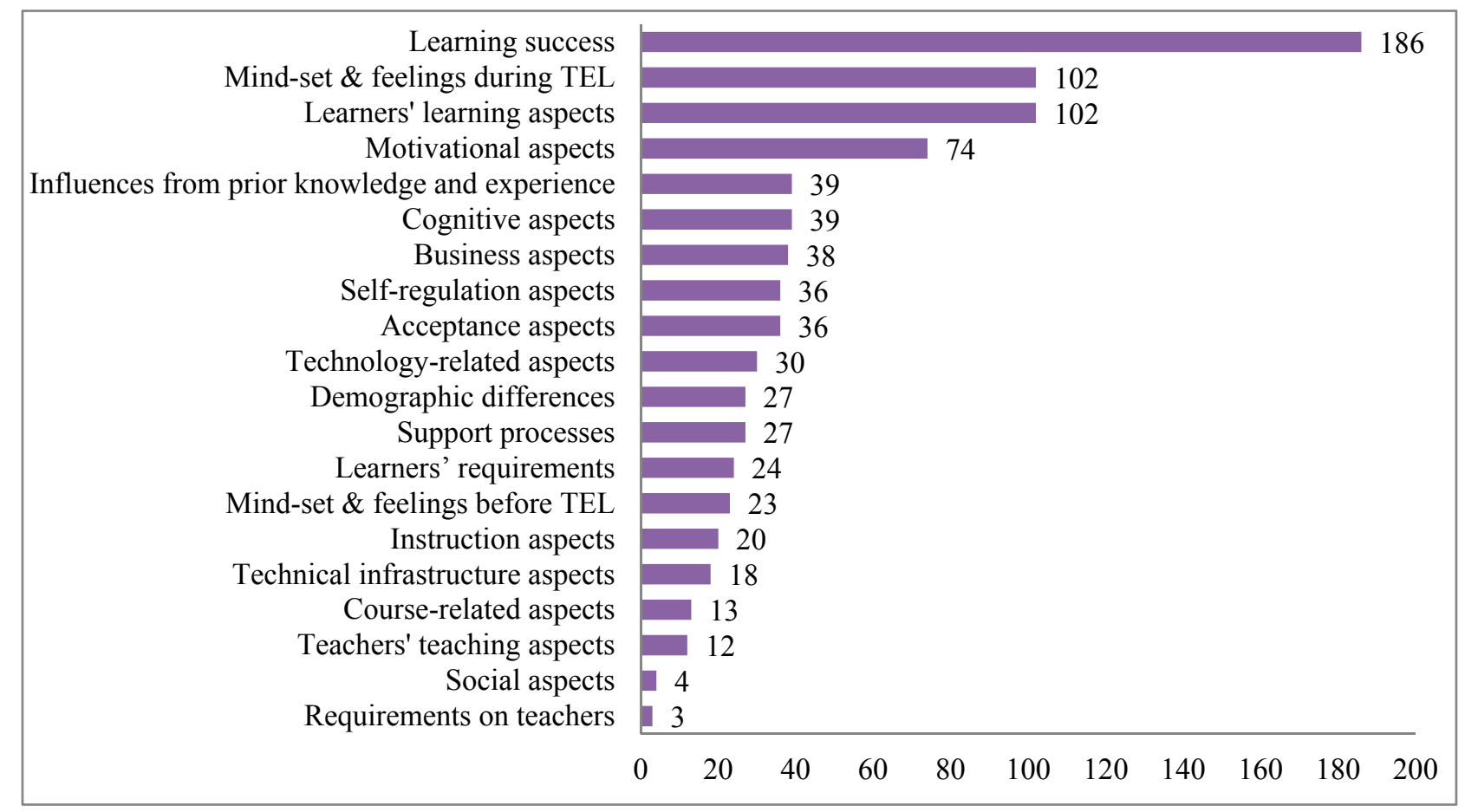

Figure 2. Count of publications assigned to the defined categories.

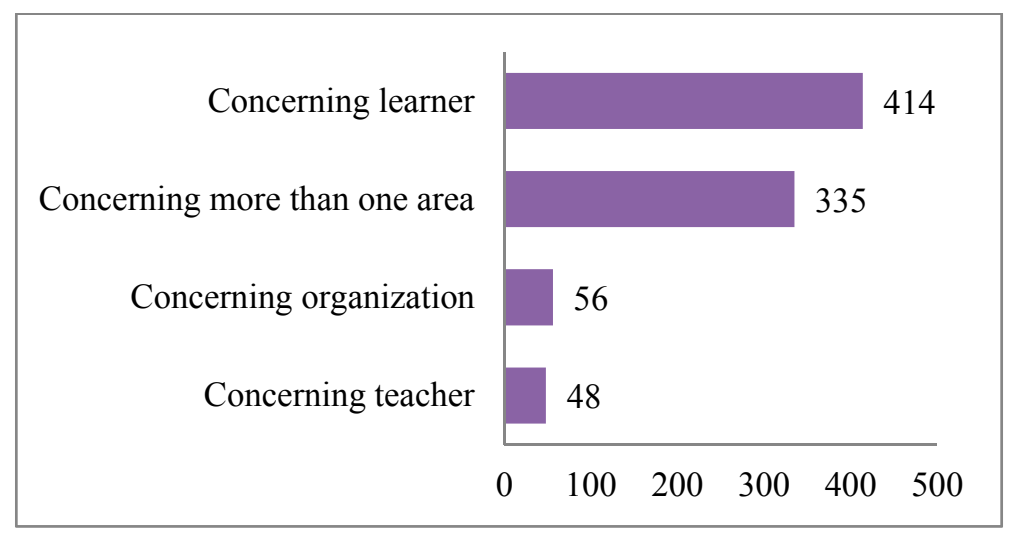

Figure 3. Count of addressed categories from the defined main areas. 
Finally, Figure 2 displays the number of analyzed publications that address aspects from a category. The chart is thus organized according to frequency. The category "learning success" is addressed the most, whereas the category "requirements on teachers" is addressed the least. Additionally, Figure 3 shows how often categories from the four main areas are addressed in the analyzed publications.

\section{Discussion}

The literature review gives an overview of aspects that could possibly be considered when implementing technology-enhanced learning approaches, based on their appearance for research purposes within a total of 4567 publications. The identified aspects are clustered into four areas and 20 categories.

The category "learning success" is thus addressed 186 times and is therefore the largest category. However, due to the fact that most publications that introduce new technology-enhanced learning approaches evaluate the new concepts to show how better learning outcomes or a better learning performance can be achieved, this is not surprising.

On the other hand, the least addressed aspects in the analyzed literature are requirements on teachers and social aspects, which is quite surprising to the authors of this study. Requirements on teachers - what they should know in order to use technology in education in the best way possible, as well as social aspects, especially when dealing with online collaboration - are important for successfully implementing technology-enhanced learning approaches and therefore should be studied more often. Moreover, all three articles concerning the requirements on teachers are identified in one journal, Teaching and Teacher Education. By implication, this also shows that in the technology-enhanced learning specialized journals of this study, Computers \& Education, Interactive Learning Environments, and Internet and Higher Education, no article covers this topic.

Additionally, only two of the analyzed publications claim that the teaching discipline itself has influence on the success of the technology-enhanced learning approach. Again, in the authors' view, although the research was limited to the analyzed journals, this issue should be examined more often.

Figure 3 shows the number of identified aspects from the four main areas. It is thus significant and related to the unusual investigation of requirements on teachers that the smallest main area deals with issues concerning teachers. This research field seems to be open, at least when considering the analyzed journals in this study.

The main area "concerning organization" is a small area as well, especially when compared to the other two areas. Out of this field, the category "business aspects" is among the top third; however, most of the identified publications in this category hardly cover these aspects, but instead mainly address other aspects. Additionally, the overall benefits and values as well as cost issues are addressed in merely four publications.

As can be seen in Table 2, the frequency of addressed categories over the year is stable. No category is addressed significantly more or less in one year between 2009 and 2014. It can therefore be said that the defined categories seem to have the same relevance for the research community over the last five years.

Out of the 12 journals that are part of this study, the most aspects, in total 535, are identified in the journal Computers \& Education. On the other hand, in Science \& Education zero aspects are identified 
and in the journals Early Childhood Research Quarterly and Economics of Education Review only one aspect is identified. Although all of these three journals cover educational issues, the usage of technology in education is only covered in a few articles in these journals.

This also shows the obvious limitations of this study. Firstly, the number of publications analyzed is vast, but still limited to the chosen journals. Secondly, it seems the chosen journals limit the identified aspects as well, since only three of them (Computers \& Education, Interactive Learning Environments, and Internet and Higher Education) are specialized in the field of technology-enhanced learning, and only publications with relations to TEL are taken into account. That is why these three journals have addressed the most aspects, although they only provided a third of all 4567 analyzed articles, with 1518 articles analyzed altogether. However, different journals cover different research areas. So, although they are not specialized in technology-enhanced learning, when articles of these journals investigate topics related to TEL, they address issues that might not be covered in TEL-specialized journals. In conclusion, the limitation to 12 high-ranked journals in the overall field of education might seem like a limitation, since only three of them specialize in TEL. However, choosing these specific journals created the broad base necessary to identify the different aspects that could possibly be considered when implementing TEL approaches. Additionally, although only journals which provide full-text download and are accessible at our home university are part of the study, this broad base is not limited further, since all publications of the finally chosen journals are accessible and with 12 high-ranked journals and a total of 4567 publications, a significant number is considered in this study.

Table 3. Comparison of identified categories/aspects and addressed aspects of existing methodologies.

\begin{tabular}{ll}
\hline \multicolumn{1}{c}{$\begin{array}{c}\text { Addressed aspects of existing } \\
\text { methodologies }\end{array}$} & \multicolumn{1}{c}{ Categories of proposed model } \\
\hline Economic aspects [3] & Business aspects \\
Technical aspects [3] & Technical infrastructure aspects, technology-related aspects \\
Didactical aspects [3] & Teachers' teaching aspects, course-related aspects, instruction aspects \\
Organizational general conditions [3] & Business aspects, technical infrastructure aspects \\
Learning outcomes [5] & Learning success \\
Social aspects [6] & Social aspects \\
Technological aspects [3] & Technical infrastructure aspects, technology-related aspects \\
Assessment techniques [7] & Support processes, learning success, course-related aspects \\
Teacher training [7] & Requirements on teachers \\
Perception [8] & Mindset \& feelings during TEL \\
Attention [8] & Cognitive aspects \\
Cognitive load [8] & Cognitive aspects \\
Coding [8] & Cognitive aspects \\
Retrieval/transfer [8] & Cognitive aspects, learning success, learners' learning aspects \\
Metacognition [8] & Cognitive aspects, learning success, self-regulation aspects \\
Marketing and recruitment [9] & Business aspects, acceptance aspects, motivational aspects \\
Financial management [9] & Business aspects \\
Quality assurance [9] & Business aspects \\
Student retention [9] & Learning success \\
Faculty development [9] & Requirements on teachers \\
Online course design [9] & Course-related aspects, technical infrastructure aspects \\
\hline
\end{tabular}


The results can be seen in Figure 1. The identified aspects cover a broad area from different research fields, such as psychology of learning, pedagogics, and informatics. However, the chosen terms in the model should be verified and if necessary narrowed down by experts in these distinct fields, in order to create a finally accurate model.

Finally, when comparing existing methodologies and the aspects addressed by them (see Introduction), it can be said that all aspects can be found in the defined categories of the proposed model of this study. Moreover, in the proposed model, firstly more categories and aspects are addressed than in all described existing methodologies together and secondly, the proposed categories are more detailed than in the described existing methodologies. Table 3 shows the detailed comparison between the addressed aspects of existing methodologies and the categories of the proposed model of this study. For this reason, the pedagogical aspects often addressed in the existing approaches are not explicitly listed because these aspects can be found in several categories of the proposed model.

\section{Conclusions and Future Work}

This literature review addresses aspects that could possibly be considered when implementing technology-enhanced learning approaches. Therefore, 4567 articles in total are analyzed and aspects related to the research question out of these articles are collected. Finally, these identified aspects are clustered and 20 categories associated with four main areas are defined in a model. This model is the answer to the given research question, hence it shows aspects that could possibly be considered when implementing approaches to TEL. An open research question regarding the model is the relation between single aspects. This might show which aspects are typically researched together. Furthermore, since the model covers a broad area of aspects from different research fields, in further steps the chosen terms and the model should be verified and if necessary narrowed down by experts from these fields, as well as checked for practicality.

On the one hand, the main results of the review show a vast number of aspects that might be considered when implementing technology-enhanced learning approaches. On the other hand, the findings also show that some important aspects have not been addressed frequently in the analyzed journals. For instance, only three publications examine requirements on teachers when it comes to technology-enhanced learning approaches, and only one publication out of 4567 analyzed covers cost issues. These issues should be investigated further in a future work. This study shows that some aspects are not frequently considered in publications. However, maybe a weighting or ranking of the identified aspects makes sense, since some aspects have to be considered unconditionally, whereas others can be considered or not. Another possible way to further investigate this result could be to carry out another literature review using the identified aspects as search terms, without being limited to journals. Moreover, extending the number of analyzed publications by taking additional journals and databases into account is a possible and necessary way to further verify the results of the given study, too.

However, although some important aspects seem not to be addressed frequently in the research area, this study provides a first model that shows a combination of several aspects that could possibly be considered when implementing technology-enhanced learning approaches. That is why, in the current state, the model could help with developing successful technology-enhanced learning approaches, since it provides this overview and helps to identify aspects that have to be considered. 
Furthermore, methods that address these aspects in detail should be added to the model. For instance, these methods can specialize in different kinds of education, such as school education, university education, vocational training, etc. in order to provide a holistic model. On account of this, the model firstly gives an overview of aspects that can be considered, and secondly provides methods to consider these aspects. Thus, the model could be used in order to develop technology-enhanced learning approaches in a structured way.

\section{Acknowledgments}

The authors want to thank Birgit Scherr for helping with designing the included figures.

\section{Author Contributions}

Patrick Schweighofer and Martin Ebner designed the concept of the article. Patrick Schweighofer performed the literature review, analyzed the data, and created the shown model. Patrick Schweighofer and Martin Ebner wrote the paper.

\section{Conflicts of Interest}

The authors declare no conflict of interest.

\section{References}

1. Schweighofer, P.; Grünwald, S.; Ebner, M. Technology Enhanced Learning and the Digital Economy: A Literature Review. Int. J. Innov. Digit. Econ. 2015, 6, 50-62.

2. Dror, I. Technology Enhanced Learning: The good, the bad, and the ugly. Pragmat. Cogn. 2008, 16, 213-215.

3. Fink, C.; Gabriel, R.; Gersch, M.; Lehr, C.; Weber, P. Lernservice-Engineering-Eine ökonomische Perspektive auf technologiegestützes Lernen. In Lehrbuch für Lernen und Lehren mit Technologien; Ebner, M., Schön, S., Eds.; Book On Demand: Norderstedt, Germany, 2011; pp. 331-338.

4. Bullinger, H.-J.; Fähnrich, K.-P.; Meiren, T. Service engineering-Methodical development of new service products. Int. J. Prod. Econ. 2003, 85, 275-287.

5. Cukusic, M.; Alfirevic, N.; Granic, A.; Garaca, Z. e-Learning process management and the e-learning performance: Results of a European empirical study. Comput. Educ. 2010, 55, 554-565.

6. Wang, Q. Designing a web-based constructivist learning environment. Interact. Learn. Environ. 2009, 17, 1-13.

7. Granic, A.; Mifsud, C.; Cukusic, M. Design, implementation and validation of a Europe-wide pedagogical framework for e-learning. Comput. Educ. 2009, 53, 1052-1081.

8. Alonso, F.; Manrique, D.; Vines, J.M. A moderate constructivist e-learning instructional model evaluated on computer specialists. Comput. Educ. 2009, 53, 57-65.

9. Rovai, A.P.; Downey, J.R. Why some distance education programs fail while others succeed in a global environment. Internet High. Educ. 2010, 13, 141-147.

10. Wu, W.-H.; Chiou, W.-B.; Kao, H.-Y.; Hu, C.-H.A.; Huang, S.-H. Re-exploring game-assisted learning research: The perspective of learning theoretical bases. Comput. Educ. 2012, 59, 1153-1161. 
11. So, H.-J.; Choi, H.; Lim, W.Y.; Xiong, Y. Little experience with ICT: Are they really the Net Generation student-teachers? Comput. Educ. 2012, 59, 1234-1245.

12. Vekiri, I. Socioeconomic differences in elementary students' ICT beliefs and out-of-school experiences. Comput. Educ. 2010, 54, 941-950.

13. Kao, C.-P.; Wu, Y.-T.; Tsai, C.-C. Elementary school teachers' motivation toward web-based professional development, and the relationship with Internet self-efficacy and belief about web-based learning. Teach. Teach. Educ. 2011, 27, 406-415.

14. Papastergiou, M. Exploring the potential of computer and video games for health and physical education: A literature review. Comput. Educ. 2009, 53, 603-622.

15. Yang, Y.-F.; Tsai, C.-C. Conceptions of and approaches to learning through online peer assessment. Learn. Instr. 2010, 20, 72-83.

16. Tsai, C.-C. Conceptions of learning versus conceptions of web-based learning: The differences revealed by college students. Comput. Educ. 2009, 53, 1092-1103.

17. Paechter, M.; Maier, B.; Macher, D. Students' expectations of, and experiences in e-learning: Their relation to learning achievements and course satisfaction. Comput. Educ. 2010, 54, 222-229.

18. Martinovic, D.; Zhang, Z. Situating ICT in the teacher education program: Overcoming challenges, fulfilling expectations. Teach. Teach. Educ. 2012, 28, 461-469.

19. Chen, J.-L. The effects of education compatibility and technological expectancy on e-learning acceptance. Comput. Educ. 2011, 57, 1501-1511.

20. Bourgonjon, J.; Valcke, M.; Soetaert, R.; de Wever, B.; Schellens, T. Parental acceptance of digital game-based learning. Comput. Educ. 2011, 57, 1434-1444.

21. Pynoo, B.; Tondeur, J.; van Braak, J.; Duychk, W.; Sijnave, B.; Duyck, P. Teachers' acceptance and use of an educational portal. Comput. Educ. 2012, 58, 1308-1317.

22. Chow, M.; Herold, D.K.; Choo, T.-M.; Chan, K. Extending the technology acceptance model to explore the intention to use Second Life for enhancing healthcare education. Comput. Educ. 2012, $59,1136-1144$.

23. Ho, C.-L.; Dzeng, R.-J. Construction safety training via e-Learning: Learning effectiveness and user satisfaction. Comput. Educ. 2010, 55, 858-867.

24. Czerniewicz, L.; Brown, C. A study of the relationship between institutional policy, organisational culture and e-learning use in four South African universities. Comput. Educ. 2009, 53, 121-131.

25. Wang, T. Rethinking teaching with information and communication technologies (ICTs) in architectural education. Teach. Teach. Educ. 2009, 25, 1132-1140.

26. Austin, K.A. Multimedia learning: Cognitive individual differences and display design techniques predict transfer learning with multimedia learning modules. Comput. Educ. 2009, 53, 1339-1354.

27. Annetta, L.A.; Minogue, J.; Holmes, S.Y.; Cheng, M.-T. Investigating the impact of video games on high school students' engagement and learning about genetics. Comput. Educ. 2009, 53, 74-85.

28. Boucheix, J.-M.; Lowe, R.K. An eye tracking comparison of external pointing cues and internal continuous cues in learning with complex animations. Learn. Instr. 2010, 20, 123-135.

29. Akyol, Z.; Vaughan, N.; Garrison, D.R. The impact of course duration on the development of a community of inquiry. Interac. Learn. Environ. 2011, 19, 231-246. 
30. Arbaugh, J.B.; Godfrey, M.R.; Johnson, M.; Pollack, B.L.; Niendorf, B.; Wresch, W. Research in online and blended learning in the business disciplines: Key findings and possible future directions. Internet High. Educ. 2009, 12, 71-87.

31. Klasnja-Milicevic, A.; Vesin, B.; Ivanovic, M.; Budimac, Z. e-Learning personalization based on hybrid recommendation strategy and learning style identification. Comput. Educ. 2011, 56, 885-899.

32. Ke, F.; Kwak, D. Online learning across ethnicity and age: A study on learning interaction participation, perception, and learning satisfaction. Comput. Educ. 2013, 61, 43-51.

33. Sánchez-Franco, M.J.; Martínez-López, F.J.; Martín-Velicia, F.A. Exploring the impact of individualism and uncertainty avoidance in web-based electronic learning: An empirical analysis in European higher education. Comput. Educ. 2009, 52, 588-598.

34. González-Gómez, F.; Guardiola, J.; Rodríguez, Ó.M.; Alonso, M.Á.M. Gender differences in e-learning satisfaction. Comput. Educ. 2012, 58, 283-290.

35. Park, S.I.; Lee, G.; Kim, M. Do students benefit equally from interactive computer simulations regardless of prior knowledge levels? Comput. Educ. 2009, 52, 649-655.

36. Margaryan, A.; Littlejohn, A.; Vojt, G. Are digital natives a myth or reality? University students' use of digital technologies. Comput. Educ. 2011, 56, 429-440.

37. Inan, F.A.; Lowther, D.L.; Ross, S.M.; Strahl, D. Pattern of classroom activities during students' use of computers: Relations between instructional strategies and computer applications. Teach. Teach. Educ. 2010, 26, 540-546.

38. Borup, J.; West, R.E.; Graham, C.R. Improving online social presence through asynchronous video. Internet High. Educ. 2012, 15, 195-203.

39. Mayrath, M.C.; Traphagan, T.; Heikes, E.J.; Trivedi, A. Instructional design best practices for Second Life: A case study from a college-level English course. Interact. Learn. Environ. 2011, 19, $125-142$.

40. Falloon, G. Young students using iPads: App design and content influences on their learning pathways. Comput. Educ. 2013, 68, 505-521.

41. Oliveira, I.; Tinoca, L.; Pereira, A. Online group work patterns: How to promote a successful collaboration. Comput. Educ. 2011, 57, 1348-1357.

42. Latham, A.; Crockett, K.; McLean, D.; Edmonds, B. A conversational intelligent tutoring system to automatically predict learning styles. Comput. Educ. 2012, 59, 95-109.

43. Darab, B.; Montazer, G.A. An eclectic model for assessing e-learning readiness in the Iranian universities. Comput. Educ. 2011, 56, 900-910.

44. Lawlor, B.; Donnelly, R. Using podcasts to support communication skills development: A case study for content format preferences among postgraduate research students. Comput. Educ. 2010, 54, 962-971.

45. Yu, F.-Y.; Wu, C.-P. Different identity revelation modes in an online peer-assessment learning environment: Effects on perceptions toward assessors, classroom climate and learning activities. Comput. Educ. 2011, 57, 2167-2177.

46. Eow, Y.L.; Ali, W.Z.b.W.; Mahmud, R.b.; Baki, R. Form one students' engagement with computer games and its effect on their academic achievement in a Malaysian secondary school. Comput. Educ. 2009, 53, 1082-1091. 
47. Hong, J.-C.; Tsai, C.-M.; Ho, Y.-J.; Hwang, M.-Y.; Wu, C.-J. A comparative study of the learning effectiveness of a blended and embodied interactive video game for kindergarten students. Interact. Learn. Environ. 2013, 21, 39-53.

48. Kim, P.; Hong, J.-S.; Bonk, C.; Lim, G. Effects of group reflection variations in project-based learning integrated in a Web 2.0 learning space. Interact. Learn. Environ. 2011, 19, 333-349.

49. Prestridge, S. The beliefs behind the teacher that influences their ICT practices. Comput. Educ. 2012, 58, 449-458.

50. Terzis, V.; Moridis, C.N.; Economides, A.A. Continuance acceptance of computer based assessment through the integration of user's expectations and perceptions. Comput. Educ. 2013, $62,50-61$.

51. Sad, S.N. An attitude scale for smart board use in education: Validity and reliability studies. Comput. Educ. 2012, 58, 900-907.

52. Dziuban, C.; Moskal, P.; Kramer, L.; Thompson, J. Student satisfaction with online learning in the presence of ambivalence: Looking for the will-o'-the-wisp. Internet High. Educ. 2013, 17, 1-8.

53. Regan, K.; Evmenova, A.; Baker, P.; Jerome, M.K.; Spencer, V.; Lawson, H.; Werner, T. Experiences of instructors in online learning environments: Identifying and regulating emotions. Internet High. Educ. 2012, 15, 204-212.

54. Teo, T. Factors influencing teachers' intention to use technology: Model development and test. Comput. Educ. 2011, 57, 2432-2440.

55. Deng, L.; Tavares, N.J. From Moodle to Facebook: Exploring students' motivation and experiences in online communities. Comput. Educ. 2013, 68, 167-176.

56. Chatzoglou, P.D.; Sarigiannidis, L.; Vraimaki, E.; Diamantidis, A. Investigating Greek employees' intention to use web-based training. Comput. Educ. 2009, 53, 877-889.

57. Guasch, T.; Alvarez, I.; Espasa, A. University teacher competencies in a virtual teaching/learning environment: Analysis of a teacher training experience. Teach. Teach. Educ. 2010, 26, 199-206.

58. Han, I.; Eom, M.; Shin, W.S. Multimedia case-based learning to enhance pre-service teachers' knowledge integration for teaching with technologies. Teach. Teach. Educ. 2013, 34, 122-129.

59. Polly, D.; Mims, C.; Shepherd, C.E.; Inan, F. Evidence of impact: Transforming teacher education with preparing tomorrow's teachers to teach with technology (PT3) grants. Teach. Teach. Educ. 2010, 26, 863-870.

60. Fulton, L.V.; Ivanitskaya, L.V.; Bastian, N.D.; Erofeev, D.A. Frequent deadlines: Evaluating the effect of learner control on healthcare executives' performance in online learning. Learn. Instr. 2013, 23, 24-32.

61. Hodges, C.B.; Murphy, P.F. Sources of self-efficacy beliefs of students in a technology-intensive asynchronous college algebra course. Internet High. Educ. 2009, 12, 93-97.

62. Shen, D.; Cho, M.-H.; Tsai, C.-L.; Marra, R. Unpacking online learning experiences: Online learning self-efficacy and learning satisfaction. Internet High. Educ. 2013, 19, 10-17.

63. Krause, U.-M.; Stark, R.; Mandl, H. The effects of cooperative learning and feedback on e-learning in statistics. Learn. Instr. 2009, 19, 158-170.

64. Pérez-Mateo, M.; Guitert, M. Which social elements are visible in virtual groups? Addressing the categorization of social expressions. Comput. Educ. 2012, 58, 1234-1246. 
65. Cheng, Y.; Ye, J. Exploring the social competence of students with autism spectrum conditions in a collaborative virtual learning environment—The pilot study. Comput. Educ. 2010, 54, 1068-1077.

66. Jara, M.; Mellar, H. Quality enhancement for e-learning courses: The role of student feedback. Comput. Educ. 2010, 54, 709-714.

67. De Wever, B.; van Keer, H.; Schellens, T.; Valcke, M. Structuring asynchronous discussion groups: Comparing scripting by assigning roles with regulation by cross-age peer tutors. Learn. Instr. 2010 , 20, 349-360.

68. Mäkitalo-Siegl, K.; Fischer, F. Stretching the limits in help-seeking research: Theoretical, methodological, and technological advances. Learn. Instr. 2011, 21, 243-246.

69. Chen, N.-S.; Kinshuk; Wei, C.-W.; Liu, C.-C. Effects of matching teaching strategy to thinking style on learner's quality of reflection in an online learning environment. Comput. Educ. 2011, 56, 53-64.

70. Hsieh, S.-W.; Jang, Y.-R.; Hwang, G.-J.; Chen, N.-S. Effects of teaching and learning styles on students' reflection levels for ubiquitous learning. Comput. Educ. 2011, 57, 1194-1201.

71. Krauskopf, K.; Zahn, C.; Hesse, F.W. Leveraging the affordances of Youtube: The role of pedagogical knowledge and mental models of technology functions for lesson planning with technology. Comput. Educ. 2012, 58, 1194-1206.

72. Seufert, T.; Schütze, M.; Brünken, R. Memory characteristics and modality in multimedia learning: An aptitude-treatment-interaction study. Learn. Instr. 2009, 19, 28-42.

73. Lehman, B.; D’Mello, S.; Graesser, A. Confusion and complex learning during interactions with computer learning environments. Internet High. Educ. 2012, 15, 184-194.

74. Liang, H.-N.; Sedig, K. Characterizing navigation in interactive learning environments. Interact. Learn. Environ. 2009, 17, 53-75.

75. Ketelhut, D.J.; Schifter, C.C. Teachers and game-based learning: Improving understanding of how to increase efficacy of adoption. Comput. Educ. 2011, 56, 539-546.

76. Peeraer, J.; van Petegem, P. Measuring integration of information and communication technology in education: An item response modeling approach. Comput. Educ. 2012, 58, 1247-1259.

77. Eynon, R.; Malmberg, L.-E. A typology of young people's Internet use: Implications for education. Comput. Educ. 2011, 56, 585-595.

(C) 2015 by the authors; licensee MDPI, Basel, Switzerland. This article is an open access article distributed under the terms and conditions of the Creative Commons Attribution license (http://creativecommons.org/licenses/by/4.0/). 